the intensive care unit, and another from the computed tomography scanner to the neurosurgeons in Nottingham.

The fire brigade came and informed us of a fire in the basement under the department. The department was full of smoke and we could not work in it for several hours.

Several patients were sent directly to wards and the ambulance service diverted patients to other hospitals. We opened the outpatient department and the day case unit and treated casualties there. This makeshift plan was difficult to implement. A few hours later when the fire was put out and the smoke dispersed, we returned with our patients to an undamaged department.

Before this experience we have had two fires started deliberately by patients in the department-one in a toilet and one in a waiting room. So the possibility of this, or indeed any, emergency department being unable to function for a period of time is always there. Fire is the most likely cause but explosions, building collapse, electrical failure, flooding, and violent affrays are others. Working in over 20 hospitals over the last 35 years, AF-M has seen all of these, but only the smoke from this fire was serious enough to cause our emergency department to be closed.)

We had no local plan in our hospital to deal with this contingency. We do now have such a plan and I am sure that other hospitals should follow our example to avoid being caught out.

There are no national guidelines for hospitals or accident and emergency departments to close, but the ambulance service has national guidelines for diverting all ambulances to other hospitals in circumstances such as these. This can easily be arranged through your local ambulance service.

A mobile field hospital could in theory be provided by the armed services. This requires quite a fair sized space to set it up. Reliable sources with experience of setting up these hospitals have told us that this takes at least 48 hours. So this is not a "quick" option, but an alternative if the emergency department is out of action.

A FRASER-MOODIE

Consultant in Accident and Emergency Medicine D HUGHES

Registrar in Accident and Emergency Medicine, Emergency Departmen Derbyshire Royal Infirmary London Road, Derby DE1 $2 Q Y$

\section{Foreign body removal from children's noses}

EDITOR,-Nasal foreign bodies are a common problem in children attending accident and emergency departments and general practice surgeries. The cooperation required is often not forthcoming as most patients are under 5 years. Instrumentation requiring restraint, sedation, or even general anaesthesia are frequently necessary. This approach may be avoided by using the positive pressure technique described below, which can be used by the parent to quickly and safely remove a nasal foreign body. ${ }^{1-3}$

A history is taken from the parent and child to determine the nature of the foreign body and which nostril is involved. If the child is cooperative, the nares can be examined to locate the foreign body but this is not absolutely necessary if there is a clear indication of which nostril is involved.

Parents are instructed to sit the child on their knee, with the nostril containing the for- eign body closest to the parent. The parent should then close the "patent" nostril using a finger and tell the child that they are going to give them "a great big kiss". Parents should then seal their lips around the child's and deliver a short sharp puff of air. The foreign body is usually extruded with one puff. It is worth holding a paper tissue close by as the foreign body is usually well covered with mucus. If this is unsuccessful several more attempts can be made without any harm. Each additional "puff" may dislodge the foreign body a little further.

The author has used this technique in over 20 cases with no failures or complications. Various objects including beads, peas, pieces of bread, and even a rabbit dropping have been removed successfully. The time from insertion of the foreign body to removal by the technique does not appear to be a factor.

Despite the simplicity of this technique it seems little used. It is easily taught to parents and can be undertaken in any setting. Use of restraints, anaesthesia, and instrumentation in frightened and distressed children can be avoided.

SARAH SCHOFIELD Principal in General Practice, North Baddesley Health Centre Norton Welch Close, Fleming Avenue, North Baddesley, Southampton SOS2 9EP

1 Backlin SA. Positive pressure technique for nasa foreign body removal in children. Ann Emer Med 1995;25:554-5.

2 Werman HA. Removal of foreign bodies of the nose. Emerg Med Clin North Am 1987;May: 253-63.

3 Cohen HA, Goldberg E, Thorev Z. Removal of nasal foreign bodies in children. Clin Pediat (Phila) 1993;32:192.

\section{Alcohol intoxication}

EDrToR,-I read with great interest the recent letters by Tovey $e t a l^{l}$ and Denning ${ }^{2}$ regarding the alcohol content of some proprietary paediatric medications and commercially available mouthwashes. Previously I was able to highlight the potential danger to children of perfumed body sprays, ${ }^{3}$ which commonly have an alcohol content of between $70-80 \%$. A child attended the accident and emergency department having consumed the contents of a "tangerine dream" perfumed body spray. She was admitted, but fortunately came to no harm. The presentation of this brand of perfumes was extremely suggestive of a soft drink. No warning was displayed on the containers, which could easily be opened by a child. This article was picked up by several newspapers and a parenting magazine. I subsequently noticed that the company selling these products had withdrawn them from their shelves. The enormous power of the media should be harnessed whenever possible in these and similar areas to protect the most vulnerable in society.

DAVID MOORE

Specialist Registrar in Accident and Emergency Medicine, Accident and Emergency Departmen Norfolk and Norwich Hospital, Brunswick Road, Norwich NR1 $3 S R$

1 Tovey C, Rana PSJB, Anderson DJ. Alcohol intoxication in a toddler. J Accid Emerg Med intoxication in

2 Denning Z. More alcohol. J Accid Emerg Med 1998;15:70.

3 Moore D, Gronow R, McCabe M. Small children may consume perfumed body spray after mistaking them for soft drinks. BMJ 1996; 313:757.

\section{Fitness to drive}

EdrToR,-Each year there are more than 15 million visits to $U K$ accident and emergency (A\&E) departments. ${ }^{1}$ Many sustain injuries, suffer from medical conditions, or have had drugs administered to them that temporarily impair the patient's ability to drive safely. Yet it is rare to hear discussion of this issue with the patient. A small prospective audit of 21 patients of driving age who were discharged from the department after the application of a limb plaster failed to demonstrate any written advice as to whether they should drive or not.

It is clear that a doctor has a legal duty to warn those patients whose driving may be impaired not to do so and to record this in the notes. ${ }^{2}$ Patients who fail to take the advice of the doctor will probably invalidate their insurance. ${ }^{3}$ The responsibility for the provision of advice for this patient group lies with each A\&E department. "Suitability to drive" is now covered in the senior house officer teaching programme.

$M$ J CLANCY P G POCKNEY Emergency Department Level C, Southampton General Hospital Tremona Road, Southampton SO16 6YD

1 Audit Commission. By accident or design. London: Audit Commission, 1995.

2 Montague A. Legal problems in emergency medicine. Oxford: Oxford University Press, 1996

3 Giddins GEB, Hammerton A. Doctor, when can I drive? A medical and legal view of the implications of advice on driving after injury or operation. Injury 1996;27:495-7.

\section{Corrections}

Out of hospital cardiac arrest and associated injury by Andrew I Jones, $M$ James Stuart, Alastair J Gray $(\mathcal{A}$ Accid Emerg Med 1998;15:191-2). We regret that because of a production problem the affiliations of the authors of this paper were omitted. They are as follows:

North Tyneside Health Care NHS Trust, Accident and Emergency, North Tyneside General Hospital, Rake Lane, North Shields, Tyne and Wear NE29 8NH A I Jones

Department of Emergency Medicine, Manchester Royal Infirmary M J Stuart

Department of Accident and Emergency, Stepping Hill Hospital, Stockport

A J Gray

Correspondence to: Dr Jones, Consultant.

$\star \star \star \star$

Implementing the Ottawa ankle rules in an Asian accident and emergency medicine department. What potential for saving? $(\mathcal{F}$ Accid Emerg Med 1998;15:132). We regret that there was a spelling error in the first author's name: this should have been Rainer rather than Stainer. 